\title{
COMUNISMO ÁCIDO VS NEOLIBERALISMO: A BATALHA PELA NOVIDADE
}

\author{
João Pedro de Souza Barros Santoro Luques ${ }^{1}$
}

\section{RESUMO}

Buscando pensar a relação entre contracultura e neoliberalismo a partir de uma perspectiva que fuja de uma abordagem determinista ou teleológica, que acaba por associar os dois através de uma espécie de necessidade, procuramos, neste artigo, desenvolver o paradigma, inaugurado por Mark Fisher, que se caracteriza por pensar este problema a partir da perspectiva da luta ideológica entre Comunismo Ácido (síntese de contracultura e política revolucionária) e a contrarrevolução neoliberal. Perspectiva essa que se destaca por, ao invés de naturalizar a relação entre neoliberalismo e contracultura, interpretar como uma costura política passível de ser desfeita.

PALAVRAS-CHAVES: Mark Fisher; Comunismo Ácido; Neoliberalismo; Contracultura.

\begin{abstract}
Attempting to think the relation between counterculture and neoliberalism in a non-teleological and non-determinist way, we aim, in this article, to develop an approach, first thought by Mark Fisher, which looks to this problem through the perspective of the ideological struggle between Acid Communism (a fusion between counterculture and revolutionary politics) and the neoliberal counterrevolution. Choosing this approach, we think we can, instead of naturalizing the relation between counterculture and neoliberalism, think it as a political suture that is capable of being undone.
\end{abstract}

KEYWORDS: Mark Fisher; Acid Communism; Neoliberalism; Counterculture.

\section{Introdução: colocando o problema}

Qual a relação entre contracultura dos anos 60 e 70 e neoliberalismo? Por um lado, nos parece indiscutível a constatação de que, a partir dos anos 70, o capitalismo (em sua fase neoliberal) assume uma carapaça "descolada", "moderna", que, claramente, nos remete a

\footnotetext{
${ }^{1}$ Mestrando em Sociologia pela Universidade Estadual de Londrina
} 


\section{Intratextes}

elementos contraculturais. Do design do Iphone, aos comerciais da Coca-Cola, das excentricidades pós-hippies de um Steve Jobs, à adoção de mesas de bilhar e videogames nas instalações da Google, a mensagem é mais ou menos, a seguinte:

O mundo comunista, bem como a IBM e as corporações dominantes do capitalismo são entediantes e monótonos [...]! O novo mundo capitalista não será assim. O novo mundo capitalista envolve desejos de uma maneira que o comunismo jamais poderá fazer (FISHER, 2020, p. 53, tradução nossa).

Ora, é tendo em vista fenômenos como estes que autores como McGuigan, por exemplo, defendem que "a boemia [ou, poderíamos dizer, a contracultura] antecipou o afrouxamento das normas sociais e o cosmopolitismo que é atualmente associado ao novo espírito do capitalismo" (2009, p. 51), ou ainda, que "desde os anos 1960, a distância tem diminuído e, de uma maneira ou de outra, a arte tem se aproximado do mundo dos negócios, em geral, e da propaganda, em particular" (2009, p. 75).

Porém, se tais constatações, colocadas assim abstratamente, são corretas, elas também podem induzir (mesmo que essa não seja a intenção dos autores) à uma conclusão, a nosso ver, equivocada: a ideia de que a contracultura tem uma espécie de germe individualista que, mesmo se não desabrochou imediatamente, se expressa inequivocamente no capitalismo neoliberal. Em suma, ganham espaço a teleologia e o determinismo e fica de fora a análise concreta das lutas de classes.

Assim, buscando superar esses impasses, o que pretendemos neste breve escrito, é, partindo das reflexões de Mark Fisher (2020) sobre o tema, pensar a formação da ideologia neoliberal e sua carapaça "moderna" a partir de sua luta contra um espectro que, mais uma vez seguindo Fisher, denominamos Comunismo Ácido.

Finalmente, além desta introdução e da conclusão, dividimos o artigo em três seções: uma primeira na qual expomos o conceito de Comunismo Ácido tal como pensado por Mark Fisher, uma segunda na qual tentamos mostrar como o neoliberalismo se constitui num combate contra o Comunismo Ácido e, por último, uma terceira seção na qual defendemos a incapacidade de políticas "locais" se constituírem como uma alternativa ao neoliberalismo.

\section{O espectro do comunismo (ácido)}

“Comunismo ácido é o nome que dei a esse espectro” (FISHER, 2018, p. 1125, tradução nossa). Assim Mark Fisher apresenta o importante conceito em seu texto (póstumo) Acid 


\section{Intratextos-}

Communism (Unfinished Introduction). Indicação essa que não deve ser lida como uma analogia, mas tomada em seu sentido mais literal. "Comunismo ácido" é um conceito que podemos enquadrar na problemática filosófica que chamamos de "espectrologia" (do inglês “hauntology”), ou seja, uma teoria sobre a agência do virtual, sobre fenômenos que, mesmo se pertencentes à outra temporalidade (seja do passado ou do futuro), agem sobre nós e, como um espectro, nos assombram (FISHER, 2014).

Neste sentido, podemos, inclusive, ler importantes domínios das ciências humanas como áreas profundamente espectrológicas. Lembremos, por exemplo, de como Freud (2006), em seu clássico Além do Princípio do Prazer, descreve o quadro de ex-combatentes assombrados pelo seu passado na guerra. Sonhos, sintomas motores, compulsões à repetição trazendo de volta a traumática experiência do conflito militar. O passado não elaborado afetando o presente. E se a psicanálise já é uma área do conhecimento dotada de significativos elementos espectrológicos, o marxismo nos parece ainda mais assombrado por fantasmas - tanto do passado, quanto do futuro. Recordemos, como no seu 18 de Brumário de Luis Bonaparte, Marx (2011) demonstra como, em todas as revoluções até então (até 1848), só surge algo de verdadeiramente novo a partir da conjuração de efeitos de um passado virtual. Cromwell, valendo-se do antigo testamento, Lutero, evocando o apóstolo Paulo, a Revolução Francesa travestindo-se de República Romana, e a Revolução de 1848 encenando (como farsa) a Revolução Francesa. Se explora a virtualidade de elementos do passado para, deles, extrair o novo. Na prática das revoluções conjura-se “[...] temerosamente a ajuda de espíritos do passado, tomam emprestados seus nomes, as suas palavras de ordem, o seu figurino, a fim de representar [...] as novas cenas da história mundial” (p. 26).

E se no 18 Brumário vemos a agência do passado, O Manifesto do Partido Comunista é, por excelência, um tratado sobre os efeitos do futuro. Afinal, o fantasma do comunismo, um possível futuro, não apenas ronda a Europa, mas também age sobre ela, gera efeitos. As classes dominantes se amedrontam frente a esse espectro. Como o próprio Marx (2013) diz, do papa ao czar, dos radicais franceses aos policiais alemães, "todas as potências da velha Europa se aliaram numa caçada santa a esse fantasma" (p. 77). Algo do futuro assombra as classes dominantes que, por sua vez, se aliam e se preparam para um exorcismo preventivo desse espectro.

Enfim, voltando ao termo Comunismo Ácido, encontramos um conceito construído justamente para dar conta de mais um destes casos nos quais uma virtualidade tem efeitos reais 


\section{Intratextes}

(e profundos). Mais especificamente, para Fischer, o neoliberalismo é uma ideologia que se constitui justamente no combate contra essa assombração. Mas o que significa, finalmente, esse conceito? De maneira sintética, a articulação entre política comunista e contracultura, "[...] a fusão dos novos movimentos sociais com o projeto comunista, uma estetização sem precedentes da vida cotidiana" (FISHER, 2018, p. 1125, tradução nossa). É a produção, a conjuração de um novo tipo de desejo, um desejo pela revolução, pela transformação social (FISHER, 2020). Um desejo, por um mundo de criação, de experimentação sensorial, por um mundo não organizado pela lógica do trabalho.

Apesar de estarmos falando de um espectro, se trata de um espectro com algumas incorporações, mesmo que bastante incompletas, com falhas e equívocos, como não poderia deixar de ser. Dentre as manifestações no campo estritamente político, talvez a experiência que mais orienta a reflexão de Fisher seja a experiência do movimento revolucionário que se deu na Itália dos anos 70 denominado Autonomia. Como nosso objeto aqui é o espectro e não suas primeiras, e ainda incompletas, manifestações, não entraremos em detalhes sobre a história da Autonomia, mas, mesmo assim, nos parece profundamente interessante o seguinte relato de Franco "Bifo" Berardi (um ex-militante do movimento) sobre este contexto:

Em maio de 1975, junto com um pequeno grupo de amigos - estudantes, militantes, feministas, trabalhadores e poetas - eu lancei a revista denominada A/Traverso.

Nós queríamos criar uma nova forma de comunicação política. Estávamos lendo Burroughs e Deleuze e Guattari, estávamos ouvindo rock, e nossa revista tinha a intenção de trazer o espírito de vanguarda (dadaísmo, futurismo, surrealismo e poesia da geração beat) para a comunicação social.

Em 1976 emergiu o movimento das rádios livres. A "Rádio Alice" começou a transmitir em fevereiro daquele ano [...].

As rádios livres ajudaram bastante na criação de uma nova cultura: uma cultura autônoma dos jovens trabalhadores que expressava sua recusa ao trabalho. Sua sensibilidade era livre do legado da ética moderna do trabalho (BERARDI, 2011, p. 178, tradução nossa).

Ou ainda, sobre a sensação que dominava o momento:

[...] as coloridas e utópicas ocupações do espaço público por multidões subversivas de "Índios Metropolitanos" e "Mao Dadaístas" [auto-nominações de grupos/vanguardas que emergiram no período] pareciam anunciar a possibilidade da felicidade coletiva, de uma sociedade menos "workaholica" [...] (BERARDI, 2011, p. 55, tradução nossa).

Nome de um destes movimentos vanguardistas, "Mao-dadaísmo" sintetiza brilhantemente o Comunismo Ácido, sua articulação de política revolucionária com o horizonte de um mundo 


\section{Intratextos}

regido, não pela lógica ascética do trabalho, mas pela valorização de experiências políticas, estéticas ou amorosas. Para citarmos a própria revista A/Traverso de Berardi e seus amigos: “Um convite para não levantar essa manhã, para ficar na cama com alguém, para fazer instrumentos musicais e dispositivos de guerra para você mesmo" (A/TRAVERSO, 1980, p. 132, tradução nossa).

Mas se o espectro do comunismo ácido se manifesta na política, o domínio no qual ele gera mais efeitos, no qual sua presença é mais sentida, é, sem dúvida, o domínio da cultura (FISHER, 2018). Talvez, o domínio mais sensível a espectros, mais apropriado para se captar efeitos do que é virtual. É justamente por isso que, para citar apenas um exemplo, em seu referido texto, Fisher faz profundas análises sobre a música A Day in the Life dos Beatles:

Essa é a qualidade de "A Day in the Life" do Sgt Pepper's, a diferença entre o calmo sonho lúcido de Lennon e as urgências da vida do trabalho (o trabalhador representado pelo canto MacCartney que pega o ônibus em monótonos segundos). Mas a escapatória das urgências é brutalmente próxima - uma vez dentro do ônibus, o personagem cantado por McCartney imediatamente cai em um sono.

Lennon soa desapaixonado, mas não distante. Tem humor, mas nenhuma familiaridade ordinária. Seu vocal parece afirmar que o sonambulismo característico do mundo do trabalho só pode ser propriamente apreendido por um tipo diferente de transe (FISHER, 2018, p. 1138, tradução nossa).

“O sonambulismo característico do mundo do trabalho só pode ser propriamente apreendido por um tipo diferente de transe". Aqui, além da reiteração da lógica do não-trabalho, vemos outra fundamental característica do comunismo ácido: o papel político da psicodelia. A busca por uma outra percepção (que pode envolver drogas, mas que não as implica necessariamente), por um delírio a partir do qual podemos enxergar o delírio cotidiano da sociabilidade capitalista. Se o social condiciona a psique, talvez, novos estados psíquicos nos ajudem a pensar um novo social. Como (décadas antes dos Beatles) apontava Walter Benjamin em seus estudos sobre o Surrealismo, trata-se da mobilização revolucionária das energias da embriaguez (DAWSEY, 2009).

Enfim, um espectro tem seus efeitos. Enfrentamento à ética do trabalho, demanda de uma outra relação com o tempo, mobilização da libido para um programa revolucionário. $\mathrm{O}$ comunismo ácido, mesmo que presente apenas virtualmente, era o esboço de um movimento fundamental por parte das classes dominadas. Abria-se a possibilidade dos subalternos ultrapassarem a burguesia na corrida armamentista da luta de classes ideológica. Isso não ficaria sem resposta. 


\section{Intratextos-}

\section{Neoliberalismo: a resposta burguesa ao comunismo ácido}

Para sustentar seus ideais, como o não trabalho, estetização da vida, a criação artística e intelectual, o Comunismo Ácido pede, como pressuposto, uma sociedade de abundância e regida pela solidariedade. Ora, é exatamente sobre estes fundamentos que a reação neoliberal concentrou seus ataques. Se o Comunismo Ácido demanda solidariedade, o neoliberalismo se sustenta no ressentimento, na anti-solidariedade. Contra o desejo coletivo, mobiliza-se o ódio contra o próximo. Difunde-se, no seio da classe trabalhadora, um ódio indignado contra qualquer coisa que o outro tenha, mas eu não (direitos trabalhistas, tempo para o lazer, educação gratuita, etc.) (FISHER, 2020). Zizek (2008) conta uma piada sobre um camponês que, ao ser interpelado por uma fada que lhe diz: "eu lhe darei o que você quiser, mas darei em dobro a seu vizinho", rapidamente responde: “arranque-me um olho!”. Não há melhor ilustração da política de afetos propagada pelo neoliberalismo.

Sistematicamente, se retira a energia das demandas coletivas e a desloca para o incômodo com o gozo do outro. E esse ressentimento, ao se espalhar, atua como uma importante peça de um projeto a partir do qual "a classe passa a ser vista como uma forma identitária de ressentimento" (FISHER, 2020, p. 207, tradução nossa). Forma-se uma identidade de classe trabalhadora que se constitui pela raiva dos "privilégios" dos universitários, das mulheres, dos negros, das pessoas dependentes do Welfare-state. Mais uma vitoriosa aplicação da tática do "dividir para reinar".

Nesse sentido, nos é bastante ilustrativo o estudo de Penny Lewis sobre a tática das classes dominantes estadunidenses de criar um antagonismo entre as classes trabalhadoras e os manifestantes contra a guerra do Vietnã. Na concepção da autora, se trata aqui de uma nítida estratégia para "criar um fosso intransponível entre os dois grupos [classe trabalhadora e jovens em protesto], uma oposição que delimitava a possibilidade de atitudes políticas ou ações compartilhadas" (LEWIS, 2013, p. 161, tradução nossa). E, como conta Lewis, estratégia essa que, uma vez desenhada, é posta em prática via uma brutal ofensiva dos aparelhos ideológicos das classes dominantes: Nixon faz famosos discursos para uma "maioria silenciosa" de americanos brancos, trabalhadores e disciplinados. A Revista Times, escolhe como homem e mulher do ano "O Americano Médio". Lotam-se as bancas com jornais e revistas contendo entrevistas de trabalhadores comuns expressando agressivas opiniões como: "Esses garotos... eles podem fazer o que eles querem em nome da reforma social [...]. Mas e o cidadão comum, e o ‘Zé ninguém'? Ele pode sair na rua e fazer isso?” (LEWIS, 2013, p. 172, tradução nossa). 


\section{Intratextes-}

Ou ainda: "Eu acho que eles [os universitários que protestavam] estão 'no bem bom' há muito tempo, e alguém tem que parar eles, porque se não parar, esse país vai à ruína” (LEWIS, 2013, p. 174, tradução nossa). A questão da guerra no Vietnã sai de cena, no lugar, entra o ressentimento contra os "privilégios" dos estudantes.

Dessa forma, aos poucos, e no calor da luta, se cria o que, posteriormente, será tomado como um dado quase natural: a imagem de uma contracultura associada ao "establishment", à uma origem de classe média-alta e relacionada com "as minorias", contrapondo-se à uma classe trabalhadora conservadora, branca e defensora da ordem. Finalmente se consolida esse "fosso instransponível". Obviamente, tal construção ideológica fora facilitada por diversos equívocos da contracultura e da esquerda em geral, como sua nítida dificuldade em pensar a política em sua dimensão mais estratégica (HALL, 1990), bem como um certo espírito de superioridade e condenação moral à aspectos conservadores de algumas práticas das classes trabalhadoras (LYOTARD, 1993). Assim, se de um lado, é necessário reconhecer "a primorosa inteligência, a feroz energia e a imaginação improvisada da contrarrevolução neoliberal” (FISHER, 2018, p. 1125, tradução nossa), por outro, não devemos esquecer que esse vitorioso contra-ataque fora imposto a um adversário paralisado por seus equívocos.

E a teoria militar nos ensina que, muitas vezes, um contra-ataque bem sucedido inverte os polos da guerra. Quem estava na defensiva passa para a ofensiva, e quem estava na ofensiva passa para a defensiva. É um pouco este o movimento do neoliberalismo. Afinal, uma vez construído o ódio contra as "elites" da contracultura, esse ódio facilmente se desliza para o apoio às políticas neoliberais, de tal forma que, não apenas se roubam as bases do Comunismo Ácido, mas as mobilizam contra ele: destruição do ensino público para acabar com esses antros de vagabundagem e rebeldia! Fim dos direitos trabalhistas (flexibilização) para que ninguém dependa dos benefícios do governo! Fim da assistência social que sustenta essa gente que não trabalha! Nas palavras de Stuart Hall em seus estudos sobre o thatcherismo, se trata de uma "cruzada para expulsar dos templos dos Estado todos os coletivistas rastejantes, Keynesianos de última moda e permissivos e frouxos apaziguadores que o ocupavam na era da socialdemocracia" (HALL, 1990, p. 72, tradução nossa).

E não confundamos as coisas. A contraofensiva neoliberal não é uma mera desculpa para fazer privatizações e contrarreformas econômicas. Aliás, unicamente a partir de um prisma economicista é completamente impossível compreender a vitória neoliberal, uma vez que ela sempre implica em colapsos econômicos. Para ficarmos só com um exemplo, no Chile de 


\section{Intratextos-}

Pinochet, após o primeiro ano de regime neoliberal, a economia já havia se contraído em 30\%. Em 1982, após quase 10 anos de neoliberalismo, a economia encontrava-se em destroços, assolada por hiperinflação, e o desemprego (3\% no período Allende) batia em 30\% (KLEIN, 2007). Ora, a explicação para a adoção dessa política econômica de autodestruição só pode ser uma: longe de ser o objetivo principal, a economia, para o neoliberalismo, se subordina à sua estratégia política. Nas palavras da própria Thatcher: "Economia é método. O objetivo é mudar o coração e a alma" (THATCHER apud SAFATLE, 2021, p. 17).

Dessa forma, como já assinalamos, essa mobilização política de pautas econômicas atua, na verdade, desestabilizando os fundamentos do Comunismo Ácido em várias frentes. Primeiramente, tem-se um processo de asfixia material. Vide, por exemplo, o caso inglês: com o corte neoliberal das bolsas do ensino superior (um valioso instrumento para os que desejavam se retirar e se dedicar exclusivamente à produção artística), com a alta de preços dos aluguéis e com o ataque à moradia social (ou seja, o ataque à possibilidade de trabalhar pouco para se dedicar à arte), e por fim, com a neoliberalização das grandes rádios e TV's públicas (BBC), destrói-se toda a estrutura que garantia a inovação na cultura popular, se estrangulam as condições de existência do "Comunismo Ácido" (LUQUES, 2021). Além disso, com o estrago feito pela política econômica neoliberal, tem-se a mobilização do desemprego enquanto fator político. A ansiedade para manter o emprego opera por si só como um potente imperativo para a disciplina. Nas palavras de Dardot e Laval (2013, p. 275, tradução nossa): “O controle da subjetividade só funciona eficientemente no contexto de um mercado de trabalho flexível onde o perigo do desemprego é o horizonte de todo trabalhador assalariado".

Em outras palavras, o neoliberalismo é inimigo de morte da tranquilidade (necessária para toda criação). Desemprego sistemático, medo de perder o precário emprego, imperativos para constantemente se atualizar. A contrarrevolução neoliberal atua corroendo, consumindo o tempo livre, o tempo da experimentação, da criação, dos afetos, do lazer (BERARDI, 2009). Enquanto a revista $\mathrm{A} /$ Traverso sugere que fiquemos na cama para fazer amor, instrumentos musicais e máquinas de guerra, o neoliberalismo impõe que jamais repousemos, para que nunca mais tenhamos paz para pensar uma outra sociedade, que gastemos todo nosso tempo, para que não tenhamos tempo de desejar a revolução.

Mas, se a mobilização do ressentimento isola a contracultura de suas bases sociais, e o desemprego, o fim das estruturas do Welfare-state e o desgaste do tempo a estrangulam, ao mesmo tempo em que ela é morta, ela também é devorada pelo neoliberalismo. A partir de uma 


\section{Intratextos-}

efetiva estratégia política, se dissolvem as bases sociais e o impulso antissistêmico do espectro do Comunismo Ácido, mas ainda resta algo. No corpo quase morto, se debatendo, ainda brilha algo vivo: um puro desejo abstrato de mudança, um impulso para o futuro, para o novo, para o moderno. É justamente isso que o neoliberalismo vai fagocitar, é esse o espólio que as classes dominantes recebem ao vencer a luta de classes ideológica. No fim, parece que o objetivo dessa longa luta, era ver quem teria o monopólio de falar pelo novo. "[...] A contracultura é espelhada pela atual forma do capitalismo. Ele não simplesmente a derrota, ele a metaboliza, a absorve, a transforma para seus próprios fins" (FISHER, 2020, p. 228, tradução nossa). Não à toa, quanto mais se consolida a vitória neoliberal, mais seus representantes parecem ser os agentes da modernização, da novidade, do design, resta à esquerda o rótulo de "velha", "atrasada", "conservadora", “decrépita".

Enfim, muito além de um simples determinismo, nos parece que a relação entre neoliberalismo e contracultura se constitui, na verdade, de um complexo processo de luta e assimilação:

\footnotetext{
Aqueles aspectos da contracultura que podiam ser apropriados foram adaptados como precursores do 'novo espírito do capitalismo', enquanto aqueles que eram incompatíveis com um mundo de excesso de trabalho foram condenados como tolices que, contraditórias à lógica da reação, eram simultaneamente perigosas e impotentes (FISHER, 2018, p. 1123, tradução nossa).
}

E aqui se revela a importância deste tipo de reconstrução das lutas passadas. Ela mostra que não existe nenhum determinismo a ligar contracultura e neoliberalismo. Mais que isso, mostra que o que foi costurado é passível de ser novamente separado, que é possível abrir a sutura operada entre neoliberalismo e a ideia de novidade. "Uma vez que optamos por abrir analiticamente esse vão entre thatcherismo e os novos tempos, pode ser possível restabelecer o diálogo rompido entre socialismo e modernidade" (HALL, 2017, p. 258, tradução nossa). Mas, para isso ocorrer, é preciso escaparmos de alguns equívocos.

\section{Sair dos caminhos equivocados: menos Avatar, mais Star Trek.}

Muitas vezes, a acirrada luta política de hoje é o dado natural de amanhã. Esse é um risco constante de quando não se escova a história a contrapelo. Assim, é justamente dentro dessa 


\section{Intratextes-}

prática de ignorar a história enquanto luta, que situamos o que alguns autores chamam de "folk politics", uma problemática tendência (majoritariamente europeia) teórico-política que emerge nas esquerdas no final do século XX, tendência essa, que defende que, para se contrapor ao capital, devemos seguir o caminho de valorizar o "tradicional", e o "primitivo", de voltar às pequenas comunidades, vistas como mais autênticas, mais ligadas à mãe natureza (WILLIAMS e SNIRCEK, 2015). Ou seja, aceita-se que a novidade e o futuro pertencem às classes dominantes, ao capital, de tal forma que o caminho para a esquerda é se retirar de cena, não mais disputar a hegemonia, mas organizar uma longa marcha em direção a um bucólico "estado de natureza".

Primeiramente, apesar dessas perspectivas (mais uma vez, predominantemente europeias) se mostrarem enquanto valorizadoras dos povos não ocidentais, elas, na verdade, são justamente o oposto. Constituindo-se, majoritariamente, por um prisma que, para nos valer de uma expressão de Peirano (2000), exotiza a diferença, tomando-a como algo a ser isolado, congelado e afastado-a de qualquer contato ou relação com o outro, tais abordagens fomentam a ideia da existência de comunidades tradicionais, idílicas, estereotipam e identitarizam os povos nãoocidentais, e ignoram a constatação de que "não existem sociedades selvagens. Somos todos selvagens, todos os selvagens são capitalistas-capitalizados" (LYOTARD, 1993, p. 127, tradução nossa).

É neste contexto que Mark Fisher, brilhantemente, pensa o filme Avatar, de James Cameron, como uma importante ilustração dessa tendência de pensamento. Um filme no qual os Na'vi, selvagens de pele azul, respeitadores do balanço natural e que ouvem os suspiros das árvores e se conectam com plantas e animais, enfrentam os interesses de malvadas corporações. Ora, o não-dito por trás dessa bela imagem (que Fisher toma com uma analogia para o que aqui chamamos de folk-politics), é o fato de que ela, dando toda a ênfase a um anti-capitalismo tradicional e primitivo, atua como um bloqueio contra a ideia de um anti-capitalismo tecnológico. Nas palavras de Fisher:

O que é ocultado na oposição entre um capitalismo predatório tecnologizado e um organicismo primitivo é, evidentemente, a possibilidade de um anticapitalismo moderno, tecnológico. É apresentando essa pseudo-oposição que Avatar funciona como um sintoma ideológico (FISHER, 2018, p. 271, tradução nossa).

Se constrói um "anti-capitalismo Avatar" para que, naturalizando o triunfo neoliberal, não pensemos num anti-capitalismo tecnológico, que evoque modernidade e prosperidade material 


\section{Intratextos-}

(digamos, para continuar no terreno das analogias com o mundo do cinema, um "anticapitalismo Star Trek").

Além disso, o que é ignorado por esse "anti-capitalismo Avatar", é justamente o funcionamento do capital, é como ele se alimenta exatamente dessas tentativas de formação de comunidades isoladas para, fagocitando-as, ganhar vitalidade: "A essência do capital é que ele, continuamente, liberta linhas de fuga - seus cientistas loucos, suas contraculturas, seus guerreiros - de maneira a abrir novos territórios para exploração" (THOBURN, 2003, p. 29, tradução nossa). Não é à toa que o neoliberalismo atuou justamente isolando a contracultura da classe trabalhadora. O Comunismo Ácido ameaça, a contracultura isolada é funcional. Fora de uma política mundial de emancipação, qualquer contracultura, qualquer exterioridade, é só matéria prima para uma futura metamorfose do capital. "A esquerda deveria mobilizar sonhos de uma economia descarbonizada, viagem espacial, economias robóticas" (WILLIAMS e SNIRCEK, 2015, p. 279, tradução nosso). Está na hora de voltarmos a reativar o desejo de transformação em escala mundial.

\section{Conclusão}

Por fim, encerramos alertando para o fato de que nosso estudo é necessariamente abstrato e exploratório, não tendo a intenção de estudar a virada neoliberal numa formação social específica, tentamos apenas pensar alguns traços fundamentais da consolidação do neoliberalismo no centro do sistema capitalista. Dessa forma, é somente por isso que nos permitimos misturar relatos da Itália, Inglaterra, Estados Unidos etc. sem muitas mediações. Além disso, também encerramos destacando o fato de que, além de teórica, nossa intenção também fora um pouco utópico-política, fora resgatar um momento no qual o capitalismo se sentia ameaçado e o neoliberalismo era luta e não fato, buscar alguns aspectos gerais de um futuro perdido, invocar "o espectro de um mundo que poderia ser livre" (FISHER, 2020, p. 6364, tradução nossa).

\section{REFERÊNCIAS}

A/TRAVESSO. Radio Alice - Free Radio. In: LONTRINGER e MARAZZI. Autonomia: PostPolitical Politics. Nova Iorque: Semiotext(e), 1980. 


\section{Intratextos}

BERARDI, Franco. After the Future. Edinburgh, Oakland e Baltimore: Ak Press, 2011.

BERARDI, Franco. Precarious Rhapsody Semiocapitalism and the pathologies of the postalpha generation. Londres: Minor Compositions, 2009.

BUTT, Gavin; ESHUN, Kodwo e FISHER, Mark. Post Punk Then and Now. Londres: Repeater, 2016.

CUBONIKS, Laboria. The Xenofeminist Manifesto : A Politics for Alienation. Londres e Nova Iorque: Verso, 2018.

DARDOT, Pierre e LAVAL, Christian. The New Way of the World: on Neoliberal Society. Londres e Nova Iorque: Verso, 2013.

DAWSEY, J. Por uma antropologia benjaminiana: repensando paradigmas do teatro na Antropologia. Mana, 15 (2): p. 349-376, 2009.

DEAN, Jodi. The Communist Horizon. Londres e Nova Iorque: Verso, 2012.

FISHER, Mark. Ghosts of my life: writings on depression, hauntology and lost futures. Winchester e Washington: Verso, 2014.

FISHER, Mark. K-Punk: The Collected and Unpublished Writings of Mark Fisher from 2004-2016. Londres: Repeater, 2018.

FISHER, Mark. Postcapitalist Desire: The Final Lectures. Londres: Repeater Books, 2020a. FREUD, Sigmund. The Penguin Freud Reader. Londres: Penguin Books, 2006.

HALL, Stuart. The Hard Road to Renewal: Tacherism and the crisis of the left. Londres: Verso, 1990.

HALL, Stuart. The meaning of new times. In: SALLY, Davison et al. Selected Political Writings The Great Moving Right Show and Other Essays. Durham: Duke University Press, 2017.

HARDT, Michael e NEGRI, Antonio. Commomwealth. Massachusetts: Harvard University Press, 2009. 


\section{Intratextes -}

KLEIN, Naomi. The State of Shock: The Rise of Disaster Capitalism. Nova Iorque: Metropolitan Books, 2007.

LEWIS, Penny. Hardhats, Hippies and Hawks: The Vietnam Antiwar Movement as Myth and Memory. Londres: Cornell University Press, 2013.

LONTRINGER e MARAZZI. Autonomia: Post-Political Politics. Nova Iorque: Semiotext(e), 1980.

LUQUES, João Pedro de Souza Barros Santoro. (Cyber)althusserianismo: a corrente subterrânea do pensamento de Mark Fisher. Disponível em: $<$ https://lavrapalavra.com/2021/04/28/cyberalthusserianismo-a-corrente-subterranea-do-pensa mento-de-mark-fisher/>. Acesso em 09 Jun 2021.

LYOTARD, Jean-François. Libidinal Economy. Indiana: Indiana University Press, 1993. McGUIGAN, Jim. Cool Capitalism. Nova Iorque: Pluto Press, 2009.

MARX, Karl. O 18 de brumário de Luís Bonaparte. São Paulo: Boitempo, 2011.

MARX, Karl. O Manifesto do Partido Comunista. In: BOTELHO, André. Essencial Sociologia. São Paulo: Penguin Classics Companhia das Letras, 2013.

PEIRANO, Mariza. Análise Antropológica de rituais. In: Série Antropológica. n. 270. Brasília, 2000.

SAFATLE, Vadimir. A economia é a continuação da psicologia por outros meios: sofrimento psíquico e o neoliberalismo como economia moral. In: SAFATLE, Vladimir; SILVA JÚNIOR, Nelson; DUNKER, Christian. Neoliberalismo como gestão do sofrimento psíquico. Autêntica, 2021.

THOBURN, Nicholas. Deleuze, Marx and Politics. Nova Iorque e Londres: Routledge, 2003.

TURNER, Victor. The Ritual Process: Structure and Anti-Structure. Nova Iorque: Cornell University Press, 1966.

TURNER, Victor. Do Liminal ao Liminóide. Mediações, Londrina, v. 17, n. 2, p. 214-257, Jul/Dez 2012. 


\section{Intratextos -}

WILLIAMS, Alex e SNIRCEK, Nick. Inventing the Future: Post Capitalism and a World Without Work. Nova Iorque: Verso, 2015.

ZIZEK, Slavoj. Lacan: Eine Einführung. Frankfurt: Fischer Verlag, 2008.

Recebido em: Junho de 2021

Aprovado em: Outubro de 2021. 